\title{
Beyond Recognition: Badiou's Mathematics of Bodily Incorporation
}

By placing Alain Badiou's philosophy under the sign of thinking infinity, the splendor, originality and radicality of the way he relates philosophy and mathematics shines forth. The scope of this relation is such that it leads directly into what thought displays as its promise and strength, that is, novel subjective change. The proposal for a radical restructuring of ontology put forth by Badiou does not emerge from a need to integrate the infinite as such (l'infini) into philosophical thought per se. This had already been achieved in philosophy previously, but mainly from a transcendent perspective. Instead, Badiou seeks to ground ontology according to infinity, here understood technically in terms of infinite sets and conceptually as pure multiplicity. From the perspective of mathematical logic, the existence of such sets is not a new finding. It has been a topic central to set theory ever since Georg Cantor postulated the General Continuum Hypothesis. ${ }^{1}$ Subsequently, Kurt Gödel showed that the negation of Cantor's Hypothesis regarding the existence of an intermediary infinite set between the natural and the rational numbers could not be proved, so that in the end there would exist but one infinite of a larger size than the set of natural numbers. The argument set forth in Being and Event bases its claim on a far more radical prospect, which is that the nonexistence of a set of an intermediate order could not be proved, thus making the Hypothesis independent from the axiomatized set theory (ZFC). In virtue of this “independence”, there might very well be many other orders of infinite sets.

The version of the General Continuum Hypothesis Badiou applies and reads in Being and Event is demonstrated in Meditation 29. Cantor, however, did not define whether the natural numbers were a set, nor even that the power set axiom involves such a set. E. Zermelo is who defined the natural numbers as a set. As far as Badiou is concerned, the set of natural numbers is the smallest infinite collection of elements, while "state" names the next infinite set, $\omega^{1}$. For any "state of the situation", there corresponds to it an excess in regard to the smallest infinite. Alain Badiou, Being and Event, trans. Oliver Feltham, Continuum, London 2008, pp. $25 \mathrm{ff}$. 
Contemporary French philosophy can be described in part as a sequence of theoretical proposals stemming from a concept of multiplicity that is irreducible to a single totalizing unit, say the One. Arguably, there has not been any proposal as broad ranging as Badiou's regarding the irreducibility of multiple infinites. The argument set up in Being and Event makes a claim on how the state of existence we inhabit, Badiou calls it the "state of the situation", can be represented in set-theoretic terms. This state can be framed as a gathering together of distinct elements and parts bounded by a single infinite, to which the elements either belong or are included as parts regardless of how many such elements the state of the situation might actually have. This description changes little when considering the very localized fields of the state of the situation in which truths, instead of opinions, beliefs or lies, are produced. Known as the "conditions" according to the lexicon Badiou composes for what is otherwise presented as a philosophical system, these fields do not exceed the boundaries of the state of the situation so long as a truth does not come to be produced within them.

Being and Event explores the thesis that the principle of radical change in any condition of the state of the situation can be recognized through the implications of the mathematical proof allowing for infinity to exceed the boundaries of a set whose elements can be counted. The measure of radical change goes by a continual creation of truth in procedures specific to each condition. Truth is thus held to refer back to an event that has ruptured the order of a condition. As such, the ontology sets out to show how the fact that radical change occurs in a condition can be both proved and understood by the set-theoretic theorem whereby a generic, indiscernible set, that is, one whose elements are not yet known, may be demonstrated as a real extension to the state of the situation. Thought conceptually, a generic, infinite set gathers together the names of processes whose achievement will have been to produce a radically new truth in a condition. The limits to which this truth can expand are those of the condition itself.

Philosophically speaking, this is a radical conclusion, though it takes getting to the later Meditations of Being and Event to grasp the considerable consequences Badiou's application has for conceptual thought. In Meditation 16, for example, he introduces the subtle paradox of the notion of event. In Meditation 35, he outlines the formal traits of a theory of subject molded upon the implications an event has for changing the terms by which truth is worked out in a condition. The Meditation reads like a list of the most polemical conclusions reached by 
French philosophers and social scientists alike since structuralism appeared to wash away the face of the subject from modern fields of conceptual inquiry. Badiou's theory of subject is post-evental. As such, it leads further than previous arguments and models into the dissolution of the 'humanist' subject. The upshot of such exploration is that the evental subject is materially indiscernible. Such is the requirement for this subject to maintain its formal structure intact prior to acquiring materiality. As soon as this process is engaged, it works against the inertial pressures produced from within a condition. These pressures can be expected to force a reduction upon the subjective process in order for it to return to the conformity of a substance-like entity.

In the following discussion, we seek to retrace the challenge to what lay ahead for Badiou's articulation of the subject. On the one hand, the requirements for thinking infinity as seen from within mathematics, by either philosophers of mathematics or those working mathematicians receptive to the philosophical problems their field fosters, point to the limitations of set theory to think infinite relations in real terms. On the other, the proposal for radical subjective change required a novel concept of a "second body", or "bodies of truth", by which to situate objects, change and worlds as they become part of the process by which a truth appears. Logics of Worlds joins these two problems in another striking proposal by which to relate philosophy and mathematics. This broad work on the process of appearing pursues the importance of thinking infinity. Its proposal works from the basis of understanding correlations between various logical possibilities regarding the appearance of truth. It thus provides a complex understanding of what bodies of truth can, and must, achieve were radical truth to have a chance to be created in a world - or, indeed, as a world.

\section{From the generic subject to the body of truth}

Philosophically speaking, the challenge for Badiou after Being and Event was to show what the structure of the subject is as it forces itself into existing in a condition in an unbounded process. In works such as Conditions and Ethics, he demonstrated how radical practice cannot be mediated by a category of transcendence. Moreover, as it is determined by a chance event, Badiou holds that the subject is not the result of a dialectical sublation. This is a key feature of an ontology deemed to be intrinsic, as the structure of subjectivation is always 
localized within a condition. ${ }^{2}$ This is a crucial point to his argument on and around the event in Being and Event, especially when illustrated from within the political condition by the figure of the activist, that "patient watchman of the void instructed by the event." ${ }^{3}$ It also lies at the subtle core of his argument regarding how the mathematics of set theory can instruct philosophy as to the formal mode by which to build a general science of being qua being. The formula "mathematics is ontology" thus warrants that the former provide a complete model for the latter, insofar as set theory is a theory of infinity. But it also provides a model for a set, the generic set, that is the extension of the set-theoretic universe as such. Neither of the operations by which sets are built and theorems derived is dialectical in nature - though they are demonstrably deductive.

Thus, while the set-theoretic universe in Being and Event may be that of infinites of different sizes and of irreducible multiplicities, what it is not is that of bodies and appearance. In Logics of Worlds, Badiou applies category theory to demonstrate the logical dynamic of appearing. Yet he also suspends the problem as to whether category theory is more adequate as an ontology. We have little choice but to follow his argument. A pressing concern arises with the risk of having truth reduced and eliminated in a hegemonic world that would tend to reduce bodies to a general social physics, in which they act merely as communicational poles, regardless of how expressive or emotional such communication might become. What bodies can do is provide a subject with freedom, but that requires truth.

According to Badiou's conviction, freedom is not linked to a body's spontaneity, nor to its intersubjective relations, but to how it literally incorporates truth. From the outset of Logics of Worlds, he declares that "the most significant stake of Logics of Worlds is without a doubt that of producing a new definition of bodies, understood as bodies-of truth, or subjectivizable bodies." Subsequent to a series of critical objections, mainly regarding the claim about set-theory being

2 While the term "intrinsic" has come to identify Badiou's ontological proposal as a result of Jean-Toussaint Desanti's critique of his ontology in Les Temps modernes, the notion of intrinsic is used throughout Being and Event to describe the non-referential nature of sets and the indiscernibility of the generic. For example, Alain Badiou, Being and Event, trans. Oliver Feltham, Continuum Books, London and New York 2005, 34 as a whole, and especially, section 7 .

3 Ibid., p. 111.

4 Alain Badiou, Logics of Worlds, trans. Alberto Toscano, Continuum, London 2009, p. 35. 
mathematics, to which we shall not return here, the coherence of the ontology as a building block for a broader system comes to depend on an adjacent claim, one warranted analytically by a structure in which logical forms are correlated. In his response to his critics, Badiou argues that such a task is captured by category theory and especially by Alexandre Grothendieck's notion of topos. ${ }^{5}$

According to Grothendieck, a topos is a "metamorphosis of the notion of space", the promise of which is to renew traditional topological spaces and geometry. ${ }^{6}$ Topos alternates in his terminology precisely with multiplicity. Grothendieck stresses that a topos can be expressed as a category, provided the structure be one of a sheave category, being that topos is like the "envelop" or "habitat" of the new geometry.7 Furthermore, his newly crafted notion of topos is unifying as it provides "a common geometric intuition for topology, algebraic geometry and arithmetic." Topos can be thus understood as involving an infinite number of categories. For the purposes of Badiou's system, it captures the potentially infinite number of correlations established between the possible modes by which to exist in givens worlds as they are structured according to distinct logical forms. From the philosophical perspective, topos theory serves Badiou as a response to the complexities faced by a generic subject as it appears as a worldly existence structured by truth-producing procedure. Topos captures a world in which truth is an exception through which to build a site of existence, of being-there. In this regard, it is understandable how Badiou considers topos

5 According to Olivia Caramello, "the introduction of the concept of Grothendieck topos stemmed from the observation that many important properties of topological spaces, such as compactness and connectedness, admit reformulations as categorically invariant properties of the associated categories of sheaves of sets; moreover, if a topological space $\mathrm{X}$ is sufficiently well-behaved (technically speaking, sober, cf. Remark 1.1.28), it can be recovered from the associated category $\mathrm{Sh}(\mathrm{X})$, as well as from the frame $\mathrm{O}(\mathrm{X})$, up to homeomorphism". Olivia Caramello, Theories, Sites, Toposes. Relating and Studying Mathematical Theories through Topos-Theoretic Bridges, Oxford University Press, Oxford UK 2018, p. 12. While Badiou does not systematically distinguish between Grothendieck topos and F.W. Lawvere's elementary topos, his reference is to the former alone (although he would regularly reference Lawvere's category theory in his 1990's Doctoral seminars.)

6 Alexandre Grothendieck, Récoltes et Semailles, Université des Sciences et Techniques du Languedoc, Montpellier, 1985-1987, p. 46 ft. 27, 56, 273 and 355. Translations are my own.

7 Ibid., p. 58.

$8 \quad$ Ibid., p. 78. 
as "among the most remarkable mathematical structures that saw the light in the 1950 and 1960s. "9

From the outset of his follow-up to his ontological proposal, Logics of Worlds faces off two idealizations of the body determining a world. The book now provides a name for the state of the situation: "democratic materialism". Characteristic of its belief system is a naturalized form of thinking by which objective existence is conceded to two broad paradigms: languages and bodies. As in Being and Event, the pivotal concept by which such thought is radically contested are truths. And the fact of truths sets the stage for a way of thinking termed a "materialist dialectic". From the perspective of truth, the latter structures another perspective on how bodies and languages ought to be thought.

Provided it be a vehicle for the radically new, irreducible, generic subject, a truth can be sustained insofar as a "second" body understood to be the creative and practical basis for conveying truth into appearance. To set up this claim, mathematics serves the aims of the system more than it did even in Being and Event. However, it is as a general theory of logic that mathematics is used to map the preconditions for the emergence of a body of truth. In this framework, logic signifies "purely and simply the cohesion of appearing." ${ }^{10}$ We may now unpack the radical terms according to which a body of truth appears.

The conceptual construction of the body is arranged in two phases. First, in the introduction to Logics of Worlds, Badiou presents the argument by which the current hegemonic system is that of bodies and languages. Plurality and primacy of bodies is set up as one of the bastions of the current order. At the same time, a process of subjective transformation of the body as a vehicle for truth takes hold of a fundamental place in the emergence of new subjective forms in which languages must also be structured accordingly. As such, "the norm of life is, quite naturally, that the genealogy of languages be adequate to the power of bodies" ${ }_{11}$. That which is opposed to this norm is the exceptional nature of truths. Truths reach appearance thanks to a body. The program is thus set out in Logics of Worlds: "Given that a subjectivizable body is a new body, this problem

9 Badiou, Logics of Worlds, p. 295.

10 Ibid., p. 100.

${ }_{11} \quad$ Ibid., p. 35. 
requires that one know what the 'appearance' of a body means, and therefore, more generally, that one elucidate what appearing, and therefore objectivity, may be." ${ }^{12}$ Such a task invokes perception as well as thought, which is a strategy deviating from the ontological field explored in Being and Event. In an allusion to Jacques Lacan's Seminar XX, the new program stipulates that truths "are required to appear bodily [en-corps] and to do so over again [encore].”13

The notion of truth Badiou had reinstated as central - and crucial to philosophy - thus confronts another crucial criterion. The definition of body refers to "that which, bearing a subjective form, confers upon a truth, in a world, the phenomenal status of its objectivity." ${ }^{14}$ From a philosophical perspective, the aforementioned "fundamental thesis" stipulates that just as ontology refers to the thought of being qua being by mathematics, "so appearing, or being-therein-a-world, is thought by logic." 15 Badiou establishes a claim according to which the dynamic by which a body of truth evokes the relational exteriority of distinct worlds can be mapped according to a Grothendieck topos, which he seeks to organize in a full exposition of its relational variations and categorical structures. What affects the truth physically is regulated by the scale of appearance as defined according to degrees or "intensities" of existence. Truths continue to respond to events whose discharge stems in this new context from generic non-existence, labelled the "inexistent" in Logics of Worlds. An event is defined as a process by which an inexistent achieves maximal intensity of existence. The theoretical program thus depends on proving how specific worlds show a capacity for sublating the inexistent of an object. ${ }^{16}$ As such, Logics of Worlds provides a theory of object without a subject.

This sudden emergence is what traces an unhindered process of subjectivation singular to a generic subject whose hold in a world is only ensured by a body. The notion of worlds and object are drafted as "a logical theory, wholly alien to any doctrine of representation or reference. ${ }^{{ }^{7} 7}$ Insofar as this theory is a coher-

\footnotetext{
12 Ibid.

13 In fact, Badiou evokes the program in a confessional tone, admitting how the problem relating body to truth "was the problem whose breadth I was yet unable to gauge". Ibid., p. 46.

14 Ibid., p. 36.

15 Ibid.

16 Ibid., Book $\mathrm{V}$ on dialectical sublation.

17 Ibid., p. 37.
} 
ent one, Logics of Worlds can be acknowledged for having achieved a common space in which to correlate three irreducible logical forms: the classical or binary, the intuitionistic and the paraconsistent. ${ }^{18}$ The particular context, or strictly speaking "world”, acquires consistency by virtue of being deduced from a specific logical form. What provides a basis for analyzing the coexistence of these worlds is the Topos category.

Logics of Worlds is replete with historical examples and formal modes by which the generic subject appears in a world. The positive analysis of the body of truth is limited to only one among four possible subjective forms. The faithful subject, as illustrated by its matheme, is the only one to align a category of body of truth to the trace of an event. ${ }^{19}$ The following is the synoptic image of this form:

$$
\frac{\varepsilon}{\phi} \Rightarrow \pi
$$

The implication of an alignment between an event trace in a world and the body of truths responding to it is what underwrites the possibility of a new present. Yet the fundamental point is how a "divided (and new) body becomes, under the bar, something like the active unconscious of a trace of the event." ${ }^{20}$ The latter points to the new framework in which what does not appear does not exist per se. Inasmuch as it is unprecedented, the new is thought from a point of indiscernibility, which evokes in this book the aforementioned inexistent

Each world is thus set as a field or territory of variable scales of appearing. A transcendental is the mechanism introduced to refer to what regulates the phenomenal diversity of appearing, or of being-there in that world. As Badiou refers to the transcendental as a "complete Heyting algebra" or "locale" ${ }_{21}$, it affords the synchronic iteration warranting the emergence of any world lodging a truth procedure. Completeness in this context refers specifically to the infinite

18 Marios Constantinou and Norman Madarasz, "Being and Spatialization: an interview with Alain Badiou”, Environment and Planning D: Society and Space 27 (2009), p. 791. Also Badiou, Logics of Worlds, p. 532.

19 Badiou, Logics of Worlds, p. 53.

$20 \quad$ Ibid., p. 53.

${ }^{21}$ Ibid., p. 167. 
possibilities of correlate worlds. The correlation that intelligibly connects the transcendental to a worldly multiplicity is also borrowed from Grothendieck's arsenal of tools, a "sheaf". Although it is "conceptually required for appearing to be bound", sheaves preserve infinity at the level of postulating worlds. ${ }^{22}$

Whereas in Being and Event the generic subject was bound to the undecidability of an event, in Logics of Worlds unfolds a sequence of immanent acts of non-conscious recognition, the practice of which proceeds to incarnate a partial but expansive body. In the diagram above, the split marking the body ' $c$ ' associates a process of recognition stripped of dependence or reference to past experience. This recurrence and the formal identity of this process implies that truth ultimately refers to a constant continuous plane. The process of producing the new present is initially emphasized as proceeding discontinuously "fragment by fragment”. As the book proceeds, this mode of producing fragments becomes one of deciding upon points, the basic insight of which stems from tracing a curve on a Euclidean plane. The body is built from successive, albeit distinct, relations in which a point is linked to previous ones in a categorical composition that is coherent (in categorical terms, is associative and composite) and provides an insightful clarity as to relations (in categorical terms, the arrows and points) constituting it. The new perspective on truth production refers to the way in which incorporation as a body of truths is mapped according to a methodological approach having the same structure as category theory.

This resulting body is neither passive in any biological sense of the term, nor is it a monistic entity, in which consciousness would be reduced to the brain, for example. As the reader is led into an immanent perspective through which the body broadens the grounds of its certainty, Badiou introduces a general, non-descript "efficacious organ" as a generic operator, internal to the category of body, from which decisions regarding the true are made. With no remote view on the structure's totality, the efficacious organ is an operation by which truth attribution builds upon points. As the points gather into a coherent category, they come to shape and objects that, in turn, respond to the circulation of truth in a specific world.

${ }^{22}$ Ibid., p. 103. 
In the end, the body of truth is distinguished from the hegemonic body form by an efficacious structure that works punctually, point by point, in "an order of affects which authorises the continuation of the process." ${ }^{23}$ Contrary to theories that tend to lend cognizing capacities mainly to the brain, consciousness is not a recognizable category regarding this procedure. In terms of a referential connection, Badiou does not provide one as regards any naturalized theories of body. This break summarizes a philosophical commitment extended to the reader as it also underscores the need for a general theory of structural as well as mathematical analyses. Without them, the reader risks reducing the efficacious organ to previous notions, theories or fields, be they psychobiological or social constructionist.

Furthermore, Logics of Worlds invites the reader to develop a novel perspective on immanence regarding the assumptions behind dialectical thinking as if to probe the very inner dynamic of sublation. In Badiou's view, it is clear "that the dialectical thinking of a singular subject presupposes the knowledge of what an efficacious body is, and of what a logical and material excess with regard to the bodies-languages system might be." ${ }^{4}$ Its magnitude depends on the amount of points linked in a process that is nothing but that of how "a subjective form is 'carried', in the phenomenon of this world, by an organized material multiplicity." ${ }_{25}$ Whereas the theory of subject is essentially formal, or formalist, the theory of body is material, thus requiring a correlation of logical theories and spatial compositions able to trace its phenomenal appearance.

Being and Event was about multiplicities and not about bodies, because its stake was not to enter into the descriptions of the historical processes of rupture and construction, which is how the body emerges in the first place. The subject lies beyond recognition for it required sustaining its indiscernibility for as long as possible in the likelihood of coming to be manifested in a condition. For all the descriptions of generic subject forms in the conditions, the system at that stage in its development did not present the means by which a faithful subject manifests itself, nor indeed was it initially contemplated should its destination be deviated and possibly suppressed. None of these immediate shortcomings weak-

\footnotetext{
3 Ibid., p. 88.

24 Ibid., p. 46.

25 Ibid., p. 27.
} 
ened the conviction over the real capability a subject has in overthrowing the order by which a condition is secured. As Badiou explains, "that is why we can present the figures of the subject right away, without yet possessing the means to think the effective or concrete becoming of a historically determinate subject." ${ }^{26}$ To achieve the latter in a theoretical setting, the methodology requires a descriptive stance.

Now, this means that Badiou's argument is not primarily a historical argument, not even ex post factum. Rather, it preserves deductive inference as fundamental to mathematical reason. ${ }^{27}$ But that is the extent of the argument, regardless of how detailed and impressive it is set out in Being and Event. Meaning that when we return to the conditions, the subject is not mathematical in material content anymore than is philosophy reduced to mathematics.

The task of the second body, that is, the variations on "subjectivated bodies", is otherwise more subtle. It presents a threshold beyond which history as a discontinuous regularity is required to speak. Still, the body is nothing without the description the process of history itself provides to it as a context in which it returns the favor and literally makes history. The process of non-visible linking of the points of its appearing is what guarantees indiscernibility to the body-subject in the same gesture as what ensures its amplification.

No matter how certain readers of Logics of Worlds attempt to steer his program, infinity is still central to the perspective adopted. The Grothendieck topos is selected due to its power to make Cantorian set theory correlate with finitist areas of mathematics. The body conceptualized by Badiou can thus aim for a perspective on its projected totality. Recapitulating, Badiou asserts "a limpid abstract formula: a post-evental body is constituted by all the elements of the site which invest the totality of their existence in their identity to the trace of the event. Or, to employ a militant metaphor; the body is the set of everything that the trace of

26 Ibid., p. 47.

${ }^{27}$ The power of inference is the entire sense by which Badiou understands mathematization in a philosophical framework. As he puts it, “'Mathematizable' means submitted to the literal power of inferences, and therefore entirely indifferent to naturalness as well as to the multiplicity of languages”. Ibid., p. 74. Cf. Badiou, Being and Event, Meditation 24, "Deduction as an Operator of Ontological Fidelity", especially section 4, on the "Triple Determination of Deductive Fidelity”, pp. 252-255. 
the event mobilizes." ${ }^{28}$ As the support to the event trace, a composition surges forth with an inferential capacity to create a new present, one responding to the truth set to build upon the event.

Such is the sense to the claim that "of the subject, there is but a theory". ${ }^{29}$ This subject incarnated is not a thing, nor object. It repels idealist postulations as it does ideological ones seeking to falsify it. As mentioned before, the subject's basic properties, as formulated from the ontology, are set out in Being and Event, Meditation 35. Its terms break with the model of substance, though nor is it the void through which an event becomes manifest. Subject does not refer either to experience, let alone to individualized lived experience. Its conceptual situation is that of being in excess to a condition. Albeit rare, its occurrence is not regulated by a law. By the time of Logics of Worlds, thinking the effective or concrete becoming of a historically determinate subject "requires a description of the body that functions as its support." 30

\section{The philosophical methodology in Logics of Worlds and its claims}

As opposed to Being and Event, the argumentative framework of Logics of Worlds takes shape according to two distinct levels. In addition to the formalism in which category and topos theory provide a general logic, Badiou introduces a recast phenomenology centered on rearticulating the notion of material being-in-the-world. In this section, we examine the phenomenological model he applies to conceptually analyze the radical correlations formalized by the category-theoretic as well as topos-theoretic structures. We question whether the boundedness typical of worlds, as expressed by the notion of horizon specific to phenomenology, might not undermine the radicality of Badiou's philosophical system. Namely, we submit that Badiou's methodology is clearly structuralist, and as such requires a clear break with phenomenology for reasons of clarity and coherence. For Logics of Worlds justifies, at least indirectly, the unexplored radical extensions of structuralism once the event and infinity are adjoined to its conceptual arsenal. Phenomenology has never been able to think infinity without returning to a theological commitment.

\footnotetext{
${ }_{28}$ Ibid., p. 467.

29 Ibid., p. 47.

3о Ibid., p. 49.
} 
The conclusive statements on the body of truth occur in Book VII of Logics of Worlds, in which one finds the recapitulation of the complete argument, the demonstration, proof and historical illustrations. While attentive to the process by which this structure appears, its simplified model suggests a form of conceptual circulation not present in the phenomenological context. The structure can be simplified according to five conditions as follows:

- An existing world, in which one comes to live, teaming with problems old and new;

- The coming to be of a site: from within this site, an event trace is received as a break in a world, not as an extension;

- Although a trace is a break, it does have elements, and proves to be something more. A body builds from elements that further integrate points from within a not entirely discernible world. As such, the body is not reducible to a trace;

- Part of this body is the efficacious organ, whose elements decide upon the points allowing for its amplification, which proceeds by means of new correlations;

- Subsequent to these correlations, new concepts envelop the efficacious part itself, a process in and through which a "new organ" is formed for the body.

While the articulation of such a model is not unfamiliar to thinkers of sexuation and critics of the gender binary, Badiou's effort in this book challenges such theories, at the very least, to ensure that incorporation is filtered by an event trace that breaks radically with the current world. We would like to assume, at least for the purposes of the current state of the situation, the coherence of Badiou's bid. To be sure, metaphoric projections are possible, as some critics of Badiou's philosophy contend..$^{31}$ Yet they can also be considered the reader's responsibility, if not deficiency. Once again, Logics of Worlds delegates responsibility to the reader to decide upon the points at which truth-valued decisions are determinate for the next steps in keeping the event trace active.

31 Cf. Vladimir Tasic, "Badiou's Logics: Math, Metaphor, and (Almost) Everything”, Journal of Humanistic Mathematics 7 (1/2017), pp. 22-45; or Shiva Rahman, "On Why Mathematics Can Not be Ontology", Axiomathes 29 (2019), pp. 289-296. 
In his chapter on "Classical Worlds" (Section V), Badiou clearly expresses his commitment to following what category theory affords in terms of mapping some worlds according to a non-binary logic. But his main focus commits to those worlds that are overwhelmingly standard, despite how the measure of appearance presented by the transcendental works as a continuous grid. Through a purely visual example of the mixture of the sun's color from a given angle against the ivy grown on a house's wall, Badiou shows how claiming a specific color for the ivy leads to an undecidable proposition as it depends on a correlation with the specific aspects of a light source. As a result, "The world of the house in the autumn evening is not classical, in the sense that it validates neither double negation nor the excluded middle." ${ }^{32}$ The occurrence of this variation in logical form should not distract from the primacy of standard logic. In the final analysis, standard logic may prove to be the surest way at preserving truth as it appears in a world.

The calculated, "objective", "minimal" or indeed "operational" phenomenology ${ }^{33}$ aims for a conceptual exposition, while mirroring, even though at a methodological distance, the formal proof. Indeed, Badiou will at times say as much, especially when stating that "without a doubt, due to the extreme rigorousness of the chains of reasoning, the formal exposition is here often more illuminating than the didactic phenomenology that precedes it." ${ }^{34}$ Through frequent references to Lacan in Book VII, to whose work he references the "second body", Badiou explicitly undermines any identification between his "operational phenomenology" and the historical methodology recognizable by that name. ${ }^{35}$ The resort to this former terminology does not cease to provoke doubt given that later Badiou explicitly rejects the kind of phenomenology that merges with the analysis of consciousness. ${ }^{36}$

If the phenomenological approach is constitutive here, then it is as from a cut. Furthermore, it is precisely the cut that raises questions as to its overall pertinence. The return to the intentional and to lived experience would hinder a theory of the new, as the transcendental ego is of no relation to the generic subject

\footnotetext{
$32 \quad$ Ibid., p. 184.

33 Ibid., p. 41, p. 128 and p. 103, respectively.

$34 \quad$ Ibid., p. 197.

35 Ibid., p. 48, p. 478 and p. 480.

$36 \quad$ Ibid., p. 48.
} 
form, for it recognizes no radical event. Badiou's phenomenology is a "description without a subject", although we might hasten to add it is one stabilized by what he terms "eternal truths". As such, it is not clear whether Badiou manages altogether to elude the theological directionality, if not finality, of phenomenology as a whole. He recognizes the risk just as much when evoking how "phenomenology, in its German variant, is indisputably haunted by religion." ${ }^{37}$ His critique of Paul Ricoeur stands as a critique of post-Husserlian phenomenology as a whole: "indestructible latency of a Christian subject at the very heart of the text." ${ }^{8}$ To go beyond the theory of subject by which phenomenology has come to be recognized, Badiou switches the register from perception to affect: "it is indeed by its affect that the human animal recognizes that it participates, through its incorporated body, in some subject of truth, we will say, with Lacan, that 'it is as incorporated that the structure makes affect'." ${ }^{39}$ By reducing the conceptual stratum of the analytic of appearance to a formal level, not even the naïve sense of prelinguistic comprehension can maintain its reference to phenomenology. For category theory shows the complexity of this level explicitly in its general theory of relations.

The question remains as to whether phenomenology can explain, let alone warrant, the indiscernible. Here we encounter the controlling instance by which an inexistent, after being propelled into a maximum intensity of appearing, keeps from being immediately drawn back to the hegemony of bodies. In fact, without efficacious organs deciding on the fragments and points that break strictly with the phallic order, there is neither guarantee, nor really directionality in the type of body that is desirable - if, that is, one can agree on whether the phallic order extends across all conditions. At any rate, at no moment has the entire tradition of phenomenology shown itself to be apt at carrying out this rupture. Although P. Maniglier and D. Rabouin in an early discussion of Logics of Worlds emphasize that there is a "structuralism" (their quotes) in the book, they do not consider the phenomenology as potentially undermining the formal topos theory..$^{40} \mathrm{We}$ could conclude that the inexistent is radically independent even from Heideg-

\footnotetext{
Ibid., p. 516.

Ibid.

Ibid., p. 480.

Patrice Maniglier and David Rabouin, “À quoi bon l'ontologie? Les mondes selon Badiou”, Critique (719/2007), pp. 279-294.
} 
ger's ontological difference and Ereignis concept, if, that is, Badiou considers Heidegger as an exemplar of phenomenology, which is not clear.

In sum, what is kept of phenomenology is the displaced methodology for constructing the theory of appearing, in which even the category of transcendental breaks with historical precedent. The broader sense of the philosophical methodology here espoused seems more structuralist than phenomenological. To be sure, structuralism breaks with the theological baggage at risk with most if not all phenomenologies. Rather surprisingly, though, Badiou prefers to sideline structuralism, or at least consider it part of a past philosophical epoch. ${ }^{41}$ And he insists: "When we say that the description of these operations makes up a complete phenomenology, we mean that the transcendental determination of the minimum, the conjunction and the envelope (or synthesis) provides everything that is needed for being-there to consist as a world." ${ }^{\prime 22}$ One could add, though, that to consist in a world, the logic behind Logics of Worlds requires relational transparency and complexity, instead of descriptive fidelity.

By contrast, philosophy caught within either subject-object or bodies-languages paradigms - democratic materialism - seems very far from understanding the sequence by which thought processes associate and correlate. The proto-paraconsistent logical framework of Martin Heidegger's Being and Time might be an exception, but French phenomenology has largely maintained its speculations bound to a single world - even when integrating the event as a key concept.

Thus far, I have been arguing that the question of preserving the theory of subject in Logics of Worlds, whether it be upheld by a phenomenological or structuralist perspective, is at least as important as how mathematics captures infinity. I say as important as, although it could, in the final analysis, be more important than.

${ }_{41}$ "I could not be structuralist because structuralism was, in its most extreme form, the abandonment of the concept of subject." This admission, one of Badiou's most explicit statements on structuralism, was made at the "Conférence d'Athènes: Introduction à L'Être et l'événement et Logiques des mondes", given at the National Technical University of Athens, on January 30, 2008. The transcription was made by R. Lopinska, available at: http://www. entretemps.asso.fr/Badiou/Athenes.htm. The conference is available online at: http:// www.youtube.com/watch? $\mathrm{v}=\mathrm{CfngSuXwWog} \&$ feature=PlayList\&p=BBC9321FB9E98Eo 3\&playnext_from=PL\&index=0\&playnext=1, (last access: July 20, 2019)

$4^{2}$ Badiou, Logics of Worlds, p. 103. 
To follow my point (which in all truth is meant to be Badiou's), mathematics is strictly defined as ontology. Naturally, mathematics is not as important in Logics of Worlds, since the latter is not about ontology, at least not primarily. Now, a number of philosophers of mathematics simply disagree with how Badiou separates category theory from mathematics. ${ }^{43}$ Contesting Badiou on this point might not be as prudent as it might first seem. Take the case of symbolic logic, which in its syllogistic form is as old as Aristotle. The modernization of symbolic logic occurs through Boolean algebra, the articulation of which was initially developed within mathematics, the refinements of which continue through the turn of the century with the axiomatization of set theory. Consider, though, how nowadays a mathematician would have an easier time finding a course in symbolic logic given in a philosophy program instead of in mathematics. If category theory is indeed a general theory of logic, no matter how unknown it still is to philosophy programs, it is not impossible to imagine it increasingly becoming more theoretically investigated in philosophy programs, just like logic has become. Depending on who is doing the talking, it already is.

The question then becomes the following: what does category theory present to Badiou if its purpose is not primarily to compensate for what is too polemical in his argument on "mathematics = ontology"? In extremely schematic form, by considering its minimal tools and definition of identity as a relation; its weak axioms, with no existential quantifier; the visibility offered to the fundamental relational activity behind the constitution of categories, as demonstrated by the "pullback" and "central object" (or subject classifier) ${ }^{44}$; and of course with the very notion of the category of sets, infinity is no longer understood at the primary level of existence. Infinity becomes a possibility of correlations and the proof aims at showing its construction to be coherent from within a material form, not of proving its existence as a set. The post-evental generic extension is not far off from that in the first place.

As one can see, the interest in infinite sets emerges through the founding principle of set theory regarding membership or belonging, which is immanent to any set and thus not considered a relation. If Badiou establishes his ontology as

43 Cf. footnote 51.

44 Alain Badiou, Mathematics of the Transcendental, trans. and ed. A.J. Bartlett and Alex Ling. Bloomsbury Press, London 2014. 
illustrative of the state of the situation, it is true that membership, the axiom of separation, axiom of foundation, power set axiom and Cartesian product capture the intrinsic form of the state of the situation. But when ontology is taken in its special sense, as describing what is singular to the generic set, which implies bracketing the axiom of foundation, then it can be argued that category theory better maps a theory of generic subjectivity, as it especially deals with the possibility of such radical change. Logical possibility might just be enough, given that the rest is up to us anyway.

Regarding Being and Event, the Gamma Diagram (Schéma Gamma) first presented in 1991 succinctly portrays the categories and steps involved in the forming of a generic subject. 45 The Diagram also makes visible the threats to fidelity a subject encounters at the level of its being. Though Badiou deliberately indexes the name "subject" to this structure, in virtue of which its material effects are made visible, it could just as well be an object, meaning that it is undecidable as to its evental form. In other words, the subject is not human per se, possibly being a set of works, theories, organizations or irreducible twos, depending on whether the event ruptures the condition of art, science, the political or love, respectively. In Logics of Worlds, the event takes the following typology of forms: "in politics, Revolution; in love, erotic liberation; in the arts, performance; and in the sciences, the epistemological break. In philosophy, we can detect it in Wittgenstein ('The world is all that is the case') as well as in Heidegger (being as coming-to-be, Ereignis)." ${ }^{\prime \prime 6}$ We can understand the evental-subject also in terms of directionality and destination, both of which nonetheless need to transfer the event trace, or situational rupturing, to a new configuration, which is none other than the body of truths. The full definition of subject in Logics of Worlds is the following. Subject is "that which imposes the legibility of a unified orientation onto the multiplicity of bodies. The body is a composite element of the world; the subject is what fixes in the body the secret of the effects it produces." ${ }^{\prime \prime 7}$ There is no temporal measure of the duration of the process, nor an indication of the tipping point when achievement lies on the horizon.

\footnotetext{
45 Alain Badiou, Conditions, trans. S. Corcoran, Continuum, London 2009, [1991], Figure 8.1, p. 121.

$46 \quad$ Ibid., p. 381.

47 Ibid., p. 46-47
} 
In the mathematical framework, category theory has been especially used to establish correlations, bridges and equivalences between different areas of mathematical work. Although it has been well over a decade since Logics of Worlds presented philosophy with this framework, what can be said with relative confidence is that the relation between this work and the ontology is concentrated in at least one concept instead of the entire undertaking. In his discussion with F Tarby in Philosophy and the Event, Badiou states: "In order to throw light on truths' relation to bodies and languages, I use a notion that is the equivalent of forcing in Being and Event, namely the concept of compatibility. A truth body is composed, in fact, of elements that are compatible in both a technical and elementary sense: they let themselves be dominated by a common element." ${ }^{\prime 3}$ And that element is the truth itself. In the dictionary of concepts offered as an appendix to Logics of Worlds, compatibility is defined as follows: "Two elements of the support-set of an object are compatible if the 'common' of their existence is the same thing as the measure of their identity." ${ }^{\prime 49}$ Following the observations made in McLarty's review of Transcendental Mathematics, Badiou's choice of the term identity instead of isomorphism could be seen as problematic from a categorical perspective, leaving doubt as to whether Badiou is not transposing the primacy of his intrinsic ontology to a thought that is only relational..$^{50}$ In the final analysis, this observation could lead us to explore an underused conceptual dimension available only to category theory.

By contrast, to hold a point is the experimental practice espoused by Badiou always from the double perspective that choice involves. "To hold a point means to hold this instance in the face of the world. Or, to have the subjective (that is, corporeal and formal) wherewithal to submit the situation to the decisional pressure of the Two." ${ }^{11}$ The theory of points is that from which radical change is enabled since it filters the degrees of the transcendental. The theory of points is also what filters the onto-logic back into the ontology.

48 Alain Badiou with Fabien Tarby, Philosophy and the Event, trans. L. Burchill, Polity Press, Cambridge 2013 [2010]), p. 116.

49 Badiou, Logics of Worlds, p. 579.

50 McLarty's reading is also voiced by Veilahti. Cf. Colin McLarty, "Review of Alain Badiou, Mathematics of the Transcendental, A. J. Bartlett and Alex Ling (trs.), Bloomsbury, 2014”, Notre Dame Philosophical Review (2014) and Antti Veilahti, "Alain Badiou's Mistake - Two Postulates of Dialectic Materialism”, Math arXiv:1301.1203v22013, 2013.

51 Badiou, Logics of Worlds, p. 590. 
With regard to the qualified communism of the second body, as demonstrated in Book VII, it is important to emphasize the growing nuances in the system that have allowed it to break with, at least the classical understanding of, binary essentialism, seen as early as in the final statement of Manifesto for philosophy. ${ }^{52}$ There, the Mallarmean Constellation, anticipating the diversification of the system occurring in Logics of Worlds a decade later, had been summoned to evoke the new poetic significance of the event. ${ }^{53}$ Therein a subject-thought is said to be disposed "point by point" to evoke a communism of the multiple. Taking hold of the divisible body is the stated task of the second body if and only if it reaches the experience of the "transhuman body". ${ }^{4}$ It is difficult not to see in this form the inscription of pure multiplicity itself.

\section{Final remarks on the oeuvre}

Several critics of Badiou's system have accused the argumentative strategy in Being and Event as lagging behind debates in mathematics regarding the broader power of topos theory to analyze the nature of ontology in comparison to set theory. An aspect of these critiques has to do with the problem of the existence of infinite sets, a view aimed at showing they do not exist. While the philosopher of mathematics has found in Logics of Worlds a formal proposal adequate to the fact that set theoretic worlds can be analysed by category theory, many philosophers have been more receptive to the work for reasons that Being and Event does not accept. The emergence of radical generic subjectivation, they claim, would not be as rare as previously surmised. Nevertheless, when Logics of Worlds is read as a new and indeed complex theory of subjectivizable body, the evidence of plurality is not forthcoming. The reader is faced with an even more subtle, and demanding, radical philosophy grounded in formalism.

Badiou has brilliantly shown how mathematics and philosophy still have much to share. As to the question of whether the destiny of mathematics is fundamentally bound to the technologies philosophy takes to be an affront to its ethical principles, it does not sufficiently justify restricting further inquiry into number,

52 Alain Badiou, Manifesto for philosophy, ed. and trans. Norman Madarasz, State University of New Press, Albany 1999, p. 109.

53 Alain Badiou, Briefings on Existence: A Short Treaty on Transitory Ontology, trans. and ed. Norman Madarasz, State University of New York Press, Albany, NY 2006 p. 168.

54 Badiou, Logics of Worlds, p. 481. 
sets, functions, and relations. As Badiou's commitment to irreducible multiplicity relies on a subject-form that is indiscernible, intrinsically non-visible and immanently bound to those who decide to take part in its validation through disparate practices, it recognizes set theory as its common ontological inscription.

Logics of Worlds was a project aimed in its preliminary stages at satisfying two important critical questions. First, if ontology is mathematics, and set theory is used as the prototype for mathematics, as in ZFC and Paul Cohen's generic extension of the set-theoretic universe, how does category theory, with its richer mathematical possibilities, stand in relation to ontology? Second, if ontology is the field of the objectless subject, how do we justify the overhauling of the phenomenal dimension merely through logic and not mathematics? We have examined both of these questions. In this sequence, we can add another thought: is the excess warranted by the Grothendieck topos on worlds, objects, change and bodies a capture of the set theoretic universe or does it merely capture a world consequent to its axioms, theorems and operational possibilities?

In his 2018 Prague keynote address ${ }^{55}$, Badiou loosened his equation of ontology and mathematics to let the former rest solely upon set theory. However, he did not relinquish the axiomatic structure of the ontology in favor of the broader relational possibilities of category theory. Regarding his defiance, is the risk we face with Being and Event's ontological framework in support of infinity, that is, of the existence of infinite sets, a new metaphysics, as some mathematicians would contend? As long as the formalism is preserved, the concept of multiplicity shown to be irreducible and the generic process stipulates an index of indiscernibility, the answer would seem to be no. By contrast, if the category and topos theories in Logics of Worlds turn out to give material support to the generic process regardless of Being and Event's ontological inquiry and refutations, it will at least have given philosophers a choice of priorities regarding the creation of an ontology. In that regard, we can all appreciate the beauty and assurance infinite sets ultimately provide to a theory of multiplicity, regardless of the relief found in the range of correlations offered by topos theory in its own capacity at preserving truth from the perspective of the infinity of relations.

55 Cf. Badiou's contribution to this volume: “Ontologie et mathématiques Théorie des Ensembles, théorie des Catégories, et théorie des Infinis, dans L’Être et l'événement, Logiques des mondes et L'Immanence des vérités”. 


\section{References}

Badiou, Alain, Being and Event, trans. Oliver Feltham, Continuum Books, London and New York 2005

- Briefings on Existence. A Short Treatise on Transitory Ontology, trans. ed. Norman Madaras, State University of New York Press, Albany, NY 2006

- Conditions, trans. Steven Corcoran, Continuum, London 2009- Le Concept de Modèle. Introduction à une Épistémologie Matérialiste des Mathématiques, Fayard, Paris 1969

- Court traité d'ontologie transitoire, Seuil, Paris 1998

- Deleuze, "la clamour de l'Être”, Hachettes, Paris 1997

- Entretien avec Peter Engelman, Quel communisme?, Bayard, Paris 2015

- Ethics. An Essay on the Understanding of Evil, trans. and intro. Peter Hallward, Verso, New York 2001

- La Tétralogie d'Ahmed, Actes Sud, Arles 2010

- L'Être et l'événement, Seuil, Paris 1988

- L'Éthique. Essai sur la conscience du mal, Hatier, Paris 1993

- L'Immanence des vérités. L'Être et l'événement 3, Fayard/Ouvertures, Paris 2018

- Le Nombre et les nombres, Gallimard, Paris 1990

- Logiques des mondes. L'Être et l'événement 2, Éditions du Seuil, Paris 2006

- Manifeste pour la philosophie, Paris, Seuil 1989

- Manifesto for philosophy, followed by two essays, ed. and trans. Norman Madarasz, State University of New Press, Albany, NY 1999

- "Mathematics and philosophy”, in Virtual Mathematics, ed. Simon Duffy, pp. 12-30, Clinamen Press, New York 2006

- Mathematics of the Transcendental, trans. and ed. A.J. Bartlett and Alex Ling. Bloomsbury Press, London 2014

- Para uma nova teoria do sujeito, Editora Relume Dumará, São Paulo 1994

- Second Manifeste pour la philosophie, Fayard/Ouvertures, Paris 2009

- Théorie du Sujet, Paris, Seuil 1982

Badiou, Alain and F. Tarby, Philosophy and the Event, trans. L. Burchill, Polity Press, Cambridge, UK 2013

Badiou Alain and Gilles Haéri, Éloge des mathématiques, Flammarion, Paris 2015

Balibar, Étienne, “Le Structuralisme : une Destitution du sujet?”, Revue de métaphysique et de morale 45 (1/2005), pp. 5-22.

Burhanuddin, Baki, Badiou's Being and Event and the Mathematics of Set Theory, Bloomsbury, London 2015

Barwise, Jon and Lawrence Moss, Vicious Circles: on the Mathematics of Non-Wellfounded Phenomena, CSLI, Stanford, CA 1996

Cantor, Georg, "Foundations of a General Theory of Manifolds: A Mathematico-Philosophical Investigation into the Theory of the Infinite” [1883], trans. William Ewald, in 
From Kant to Hilbert: A Source Book in the Foundations of Mathematics, Volume II., ed. Ewald, Oxford University Press, Oxford 1996

- Contributions to the Founding of the Theory of Transfinite Numbers, trans. Philip Jourdain, Dover, London 1915

Carmello, Olivia, Theories, Sites, Toposes. Relating and Studying Mathematical Theories through Topos-Theoretic Bridges, Oxford University Press, Oxford 2018

Cohen, P. J., "The Independence of the Continuum Hypothesis”, Proceedings of the National Academy of Sciences of the United States of America 50 (6/1963), pp. 1143-1148

- Proceedings of the National Academy of Sciences of the United States of America 51 (1/1964), pp. 105-110.

Constantinou Marios and Norman Madarasz, "Being and Spatialization: an interview with Alain Badiou”, Environment and Planning D: Society and Space 27 (2009), pp. 783-795

Desanti, Jean-Toussaint, "Quelques remarques à propos de l'ontologie intrinsèque d'Alain Badiou”, Les Temps Modernes (526/1990), pp. 61-71

Fraser, Zachary, "The Law of the Subject: Alain Badiou, Luitzen Brouwer and the Kripkean Analyses of Forcing and the Heyting Calculus”, The Journal of Natural and Social Philosophy 2 (1-2/2006), pp. 94-133

Gödel, Kurt, “What is Cantor's Continuum Problem?”, in Kurt Gödel: Collected Works, vol II., ed. Solomon Feferman, et. al., pp. 1938-1974, Oxford University Press, New York 1995

- "The Consistency of the Axiom of Choice and the Generalized Continuum Hypothesis", Proceedings of the national academy of sciences of the U.S.A. 24 (1938), pp. 556-557

Grattan-Guinness, I., The Search for Mathematical Roots. (1870-1940): Logic, Set Theories and Foundations of Mathematics from Cantor through Russell to Gödel, Princeton University Press, Princeton, NJ 2000

Grothendieck, Alexandre, Récoltes et Semailles, Université des Sciences et Techniques du Languedoc, Montpellier 1985-1987

Hallward, Peter and Knox Peden (eds.), Concept and Form, Verso, New York 2012

Heidegger, Martin, Being and Time, trans. John Macquarrie and Edward Robinson, Harper and Row, New York 1962

Heller, Michael and W. Hugh Woodin, Infinity: New Research Frontiers, Cambridge University Press, New York 2011

Hunter, Ian, “Heideggerian Mathematics: Badiou's Being and Event as Spiritual Pedagogy”, Representations 134 (Spring 2016), pp. 116-156

Jech, T., Set Theory, Springer-Verlag, Berlin 2003

Lacan, Jacques, Séminaire livre XX: Encore (1972-1973), ed. Jacques-Alain Miller, Editions du Seuil, Paris 1999

- Autres écrits, Seuil, Paris 2001 
Lautman, Albert, Les mathématiques, les idées et le réel physique, Librairie Philosophique, J. Vrin, Paris 2006

Lejewski, Czeslaw, “Ontology and Logic”, in Philosophy of Logic, ed. Stephen Korner, pp. 1-63, Basil Blackwell, Oxford 1976

Madarasz, Norman, O Realismo Estruturalista: sobre o imanente, o intrínseco e o inato, Filosofia e interdisciplinaridade, Editora fi, Brasil 2015

- O Múltiplo sem Um. Uma apresentação do sistema filosófico de Alain Badiou, Editora Ideias e letras, São Paulo 2011

- “On Alain Badiou's treatment of Category Theory in view of a Transitory Ontology", in Alain Badiou: Philosophy and Its Conditions, p. 23-43, Suny Series, Albany, NY 2005

Malicki, Maciej, "Mathemes and Mathematics. On the Main Concepts of the Philosophy of Alain Badiou”, ArXiv, May 2014, available at: 2014arXiv1406.0059M

Maniglier, Patrice et Rabouin, David, "À quoi bon l'ontologie ? Les mondes selon Badiou », Critique (719/2007), pp. 279-294

Marquis, Jean-Pierre, “Category Theory”, The Stanford Encyclopedia of Philosophy, ed. Edward N. Zalta [forthcoming]

Mclarty, Colin, “Como Grothendieck simplificou a geometria algébrica”, trans. Norman R. Madarasz, Revista Veritas 61 (2/2016), pp. 276-294

- "Review of Alain Badiou, Mathematics of the Transcendental, A. J. Bartlett and Alex Ling (trs.), Bloomsbury, 2014”, Notre Dame Philosophical Review (2014), available at: https://ndpr.nd.edu/news/mathematics-of-the-transcendental/

- “Review of Simon Duffy, ed., Virtual Mathematics”, Australasian Journal of Philosophy 86 (2008), pp. 332-36

- "The Uses and Abuses of the History of Topos Theory", British Journal for the Philosophy of Science, 41 (1990), pp. 351-75

Putnam, Hilary, Philosophy of Logic, Routledge Revivals, London 2011

Rahman, Shiva, “On Why Mathematics Can Not be Ontology”, Axiomathes 29 (2019), pp. 289-296

Tasic, Vladimir, “Badiou's Logics: Math, Metaphor, and (Almost) Everything”, Journal of Humanistic Mathematics 7 (1/2017), pp. 22-45

Veilahti Antti, “Alain Badiou's Mistake. Two Postulates of Dialectic Materialism”, Math arXiv:1301.1203v22013 (2013)

Watkin, William, Badiou and Indifferent Being. A Critical Introduction to Being and Event, Bloomsbury, London 2017 